\title{
Is Temporal Association Between Popliteal-Sciatic Block and Nerve Injury \\ Sufficient Evidence to Assign Etiology?
}

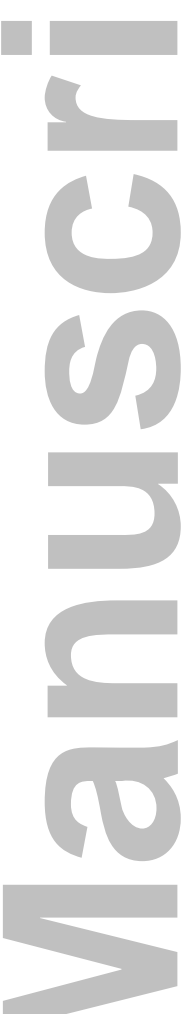

\author{
Michael J. Barrington, MBBS, FANZCA, $\mathrm{PhD}^{\&}$ \\ Andrew T. Gray, MD, PhD* \\ \& Department of Anaesthesia \\ University of Melbourne \\ St. Vincent's Hospital \\ Melbourne, Victoria, Australia \\ ${ }^{*}$ Department of Anesthesia and Perioperative Care \\ University of California, San Francisco \\ Zuckerberg San Francisco General \\ San Francisco, CA 94110
}

Address correspondence to Dr. Gray, Department of Anesthesia and

Perioperative Care, Building 5, Room 3C-38, Zuckerberg San Francisco General, University of California, San Francisco, CA 94110. Telephone 415-206-3250;

FAX 415-206-6014; email graya@anesthesia.ucsf.edu

\footnotetext{
We confirm that we have read the Journal's position on issues involved in ethical publication and affirm that this report is consistent with those guidelines.

None of the authors has any conflict of interest to disclose.

Keywords: popliteal block, sciatic neuropathy, regional anesthesia, perioperative nerve injury, electrodiagnostic study, tourniquet ischemia

Word count: 440
}

This is the author manuscript accepted for publication and has undergone full peer review but has not been through the copyediting, typesetting, pagination and proofreading process, which may lead to differences between this version and the Version of record. Please cite this article as doi:10.1002/ mus.26020. 


\section{Is Temporal Association Between Popliteal-Sciatic Block and Nerve Injury Sufficient Evidence to Assign Etiology?}

\section{To the Editor:}

We thank Aubuchon for reporting a potential association between popliteal-sciatic block and sciatic neuropathy based on electrodiagnostic findings. ${ }^{1}$ However, our view is that the temporal association between poplitealsciatic block and nerve injury is not sufficient evidence to assign etiology, and other possible etiologies should be considered. For many surgeries (such as shoulder, hip, or knee arthroplasty), the incidence of postoperative nerve injury is the same regardless of anesthetic technique used. ${ }^{2}$

Determining the etiology of postoperative nerve injury is complex and distinguishing surgical, patient and anesthetic factors is often challenging. The incidence of peripheral nerve damage with long term neurologic deficit due to peripheral regional anesthesia is approximately one in every three thousand block procedures. ${ }^{3}$ An important surgical factor is the use of the pneumatic tourniquet which can result in denervation changes on electromyography (EMG). ${ }^{4}$

EMG alone cannot determine what caused the injury. A thorough history and physical examination is also critical, and any neurologic deficit should be concordant with the expected distribution of the nerve block if a block-related 
cause is assigned. Imaging studies (such as ultrasound or MRI) in the relevant anatomic region may be indicated. ${ }^{5}$ It is well documented that the incidence and severity of postoperative nerve injury decrease over time after the injury, ${ }^{3}$ but the present report does not describe this.

The clinical features of block-related nerve injury and normal surgical recovery often overlap. For example, following foot surgery it is not uncommon for paresthesias from the surgical incisions to persist. In this current report, important details regarding the blocks are missing (anatomic location, injection pressure, local anesthetic and adjuncts, volume, sedation and wakefulness). A scholarly approach would be to tabulate and/or analyze all 45 sciatic neuropathy cases referred to your lab and include information such as: patient demographics, surgical type, use of pneumatic tourniquet, neurologic features and their onset, timing of referral, EMG parameters, and imaging studies. In summary, while respecting the authors' expertise, we are concerned that key data was not presented and perioperative insults other than sciatic blockade were not considered.

We welcome further input regarding the importance of the short head of biceps femoris EMG. Our understanding is that an abnormal short head of biceps EMG demonstrates an injury proximal to the innervation of this muscle. In cases of suspected distal sciatic nerve injury in the popliteal fossa, can the authors comment on how accurately the short head of biceps EMG can localize the site of injury or abnormal findings? Specifically, can the EMG distinguish an 
injury at the popliteal fossa from an injury mid-thigh? Was this EMG performed in all cases and do technical issues relating to body habitus reduce its reliability?

\section{Michael J. Barrington, MBBS, FANZCA, PhD}

Department of Anaesthesia and Acute Pain Medicine, St. Vincent's Hospital

University of Melbourne

Melbourne, Victoria, Australia

Andrew T. Gray, MD, PhD

Department of Anesthesia and Perioperative Care

University of California, San Francisco

San Francisco, CA USA

\section{References}

1. Aubuchon A, Arnold WD, Bracewell A, Hoyle JC. Sciatic neuropathy due to popliteal fossa nerve block. Muscle Nerve 2017;56:822-824.

2. Brull R, Hadzic A, Reina MA, Barrington MJ. Pathophysiology and Etiology of Nerve Injury Following Peripheral Nerve Blockade. Reg Anesth Pain Med 2015;40:479-490.

3. Neal JM, Barrington MJ, Brull R, Hadzic A, Hebl JR, Horlocker TT, Huntoon MA, Kopp SL, Rathmell JP, Watson JC. The Second ASRA Practice Advisory on Neurologic Complications Associated With Regional Anesthesia and Pain 
Medicine: Executive Summary 2015. Reg Anesth Pain Med 2015;40:401-430.

4. Dobner JJ, Nitz AJ. Postmeniscectomy tourniquet palsy and functional sequelae. Am J Sports Med 1982;10:211-214.

5. Barrington MJ, Morrison W, Sutherland T, Tay VS, Watson JC. Case scenario: postoperative brachial plexopathy associated with infraclavicular brachial plexus blockade: localizing postoperative nerve injury. Anesthesiology 2014;121:383387.
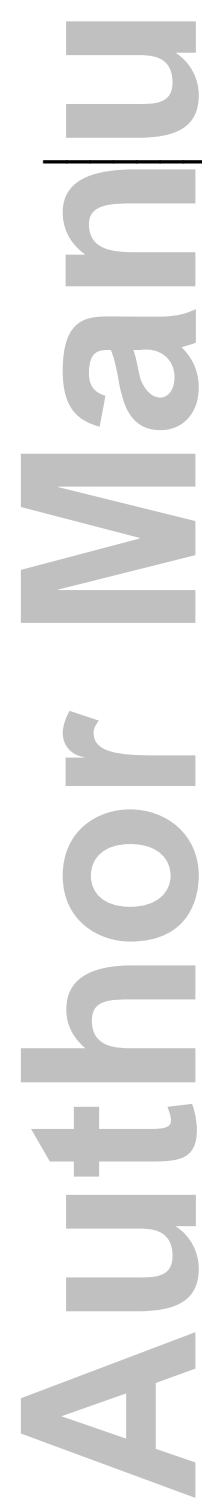


\section{University Library}

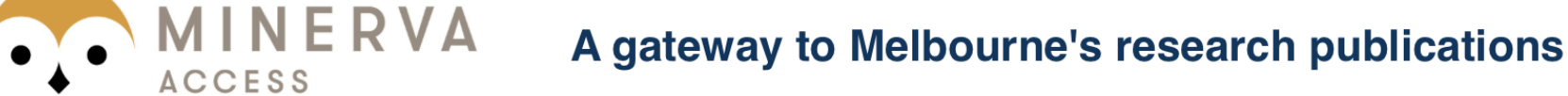

Minerva Access is the Institutional Repository of The University of Melbourne

Author/s:

Barrington, MJ;Gray, AT

Title:

Is temporal association between popliteal-sciatic block and nerve injury sufficient evidence to assign etiology?

Date:

2018-03-01

Citation:

Barrington, M. J. \& Gray, A. T. (2018). Is temporal association between popliteal-sciatic block and nerve injury sufficient evidence to assign etiology?. MUSCLE \& NERVE, 57 (3), pp.E113-E113. https://doi.org/10.1002/mus.26020.

Persistent Link:

http://hdl.handle.net/11343/294066 